Atmos. Chem. Phys., 17, 11673-11681, 2017

https://doi.org/10.5194/acp-17-11673-2017

(C) Author(s) 2017. This work is distributed under

the Creative Commons Attribution 3.0 License.

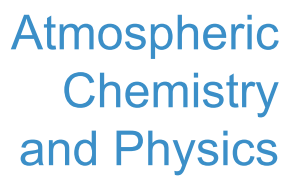

(c) (i)

\title{
Role of atmospheric circulations in haze pollution in December 2016
}

\author{
Zhicong Yin ${ }^{1,2}$ and Huijun Wang ${ }^{1,2,3}$ \\ ${ }^{1}$ Key Laboratory of Meteorological Disaster, Ministry of Education / Joint International Research Laboratory of Climate and \\ Environment Change (ILCEC) / Collaborative Innovation Center on Forecast and Evaluation of Meteorological Disasters \\ (CIC-FEMD), Nanjing University of Information Science \& Technology, Nanjing 210044, China \\ ${ }^{2}$ Nansen-Zhu International Research Centre, Institute of Atmospheric Physics, Chinese Academy of Sciences, Beijing, China \\ ${ }^{3}$ Climate Change Research Center, Chinese Academy of Sciences, Beijing, China
}

Correspondence to: Zhicong Yin (yinzhc@163.com)

Received: 4 June 2017 - Discussion started: 13 June 2017

Revised: 12 August 2017 - Accepted: 14 August 2017 - Published: 28 September 2017

\begin{abstract}
In the east of China, recent haze pollution has been severe and damaging. In addition to anthropogenic emissions, atmospheric circulations and local meteorological conditions were conducive factors. The number of December haze days over North China and the Huanghuai area has increased sharply since 2010 and was greatest in 2016. During 2016, the most aggressive control measures for anthropogenic emissions were implemented from 16 to 21 December, but the most severe haze pollution still occurred, covering approximately $25 \%$ of the land area of China and lasting for 6 days. The atmospheric circulations must play critical roles in the sub-seasonal haze events. Actually, the positive phase of the East Atlantic-West Russia pattern in the middle troposphere strengthened the anomalous anti-cyclone over the $\mathrm{NH}$ area that confined vertical motion below. The associated southerly anomalies made the cold air and surface wind speed weaker, but enhanced the humid flow. Thus, the horizontal and vertical dispersion of atmospheric particulates was suppressed and the pollutants gathered within a narrow space. In December 2016, these key indices were strongly beneficial for haze occurrence and combined to result in the severest haze pollution. The influences of the preceding autumn sea surface temperature near the Gulf of Alaska and the subtropical eastern Pacific, October-November snow cover in western Siberia, and associated physical processes on haze pollution are also discussed.
\end{abstract}

\section{Introduction}

Because of its enormous adverse effects, haze pollution has become one of the most serious environmental problems in China, attracting considerable scientific and social attention. Increasing anthropogenic emissions have been contributing to severe haze pollution in China and have mainly impacted on the long-term trend of haze days (Wang et al., 2013). However, interannual variations of haze days were affected by meteorological conditions (Wang et al., 2015; Yang et al., 2016; Wang and Chen, 2016). At present, aerosols have approached saturation in the atmosphere (Zhang et al., 2013). When the horizontal and vertical dispersion of atmospheric particulates is impeded, haze weather tends to occur (Yin et al., 2015a). Therefore, anomalous atmospheric circulations play a key role in the formation of heavy haze pollution in winter (December-February; Chen and Wang, 2015). From the hemispheric and regional perspective, the positive phase of the Arctic Oscillation (Yin et al., 2015b), the weak East Asia winter monsoon (Li et al., 2015; Yin et al., 2015b), and the positive phase of the East Atlantic-West Russia (EA/WR) teleconnection (Yin et al., 2017) contribute to the occurrence of winter haze by modulating local anti-cyclone anomalies over North China. As a key local circulation, this anomalous anti-cyclone resulted in descending motion (Wu et al., 2017) that contributed to a reduction in the height of the planetary boundary layer (PBL). Other conducive weather conditions include reduced surface wind speed and enhanced humidity in the lower atmosphere (Ding et al., 2014). Such weather conditions trap abundant atmospheric particles and moisture, 
leading to a high concentration of pollutants. Furthermore, the frequency and persistence of weather conditions conducive to the Beijing winter severe haze events were projected to increase substantially under climate change in the future (Cai et al., 2017).

On the sub-seasonal timescale, haze pollution in December is quite serious and has distinct characteristics, but it has not received adequate attention. As shown in Fig. 1, there were eight wide-scale haze pollution events in China in 2016. During six of these events, the highest $\mathrm{PM}_{2.5}$ concentration was observed in North China. During 2016, haze pollution was most severe during 16-21 December, with the highest $\mathrm{PM}_{2.5}$ concentration of $1100 \mu \mathrm{g} \mathrm{m}^{-3}$ in the whole of North China and the Huanghuai area $\left(\mathrm{NH}\right.$, located at $30-41^{\circ} \mathrm{N}$, $110-120^{\circ} \mathrm{E}$ ) where more than 300 million people live. The affected area was $2680000 \mathrm{~km}^{2}$. There, the area affected by severe haze was $710000 \mathrm{~km}^{2}$, which was close to the total area of the preceding seven episodes in 2016. In addition, its duration was 6 days, which was approximately twice as long as the other haze episodes (Fig. 1b). Furthermore, for the past 38 years, the number of December haze days (DHD) over the $\mathrm{NH}$ area $\left(\mathrm{DHD}_{\mathrm{NH}}\right)$ was greatest in 2016 (Fig. 1a). Since 2010, DHD $_{\mathrm{NH}}$ has experienced a sharp increase and reached 21.5 in 2016, meaning that the air was polluted for approximately $70 \%$ of the days. Because air pollution is regulated and controlled by the Chinese Government, annual pollutant emissions varied slowly (Mathews and Tan, 2015), but this could not fully explain the sharp increase in $\mathrm{DHD}_{\mathrm{NH}}$ after 2010. In particular, although vehicle control and production restriction measures were timely, extensive, and strictly implemented, haze pollution was still severe during 16-21 December. The effects of emission reduction measures on air pollutants were efficient and proven during the 2015 World Championships and Parade (WCP) held in Beijing (Zhou et al., 2017). Thus, understanding the role of atmospheric circulation in extreme haze pollution in December 2016 is vital, and this is analyzed in this paper.

The data and methods are described in Sect. 2. In Sect. 3, we analyze the roles of global and regional atmospheric circulations in haze in December 2016. Then, a synoptic case (i.e., the severest haze pollution in 2016) was studied to understand the physical mechanisms in more detail in Sect. 4. A discussion of our results and the main conclusions of the study are included in Sect. 5.

\section{Datasets and methods}

The geopotential height at $500 \mathrm{hPa}$ (Z500), zonal wind at $200 \mathrm{hPa}$ (U200), wind at $850 \mathrm{hPa}$, wind at the surface, sea level pressure (SLP), surface air temperature (SAT), surface relative humidity, and vertical wind (omega) were available on the website of the National Centers for Environmental Prediction/National Center for Atmospheric Research (NCEP/NCAR). These NCEP/NCAR reanalysis I datasets
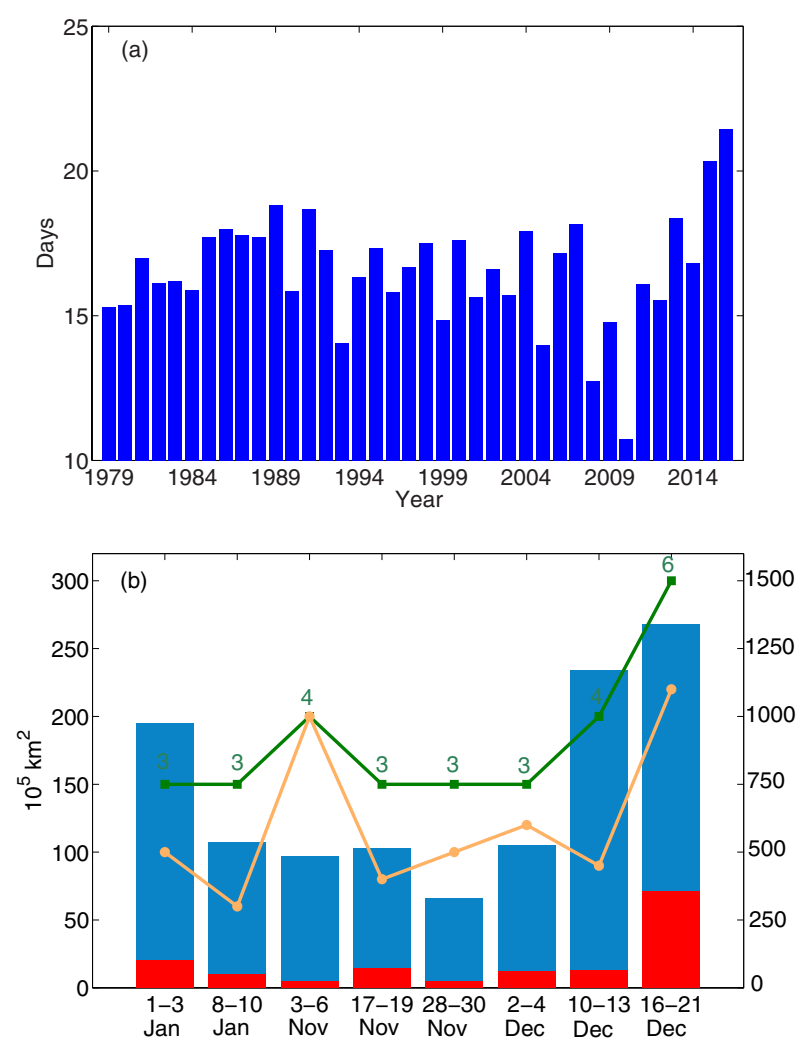

Figure 1. (a) The variation of $\mathrm{DHD}_{\mathrm{NH}}$ from 1979 to 2016 and (b) the parameters of the main haze processes in China in 2016: haze (blue bar) and severe haze (red bar) covered area (left $y$-axis), the maximum $\mathrm{PM}_{2.5}$ concentration (yellow line, right $y$-axis, unit: $\mu \mathrm{g} \mathrm{m}^{-3}$ ) and the number of days lasted (green line and number).

had a horizontal resolution of $2.5^{\circ} \times 2.5^{\circ}$ from 1948 to 2016 (Kalnay et al., 1996). For the representativeness of vertical dispersion, the $1^{\circ} \times 1^{\circ}$ height of the PBL was also used here, but was derived from the ERA-Interim dataset (Dee et al., 2011). The monthly mean extended reconstructed SST datasets with a horizontal resolution of $2^{\circ} \times 2^{\circ}$ from 1979 to 2016 were obtained from the National Oceanic and Atmospheric Administration (Smith et al., 2008). The monthly $1^{\circ}$ by $1^{\circ}$ snow cover data were supported by Rutgers University (Robinson et al., 1993). The EA/WR pattern consisted of four anomalous centers and the positive phase is associated with positive anomalous height over Europe and northern China, and negative anomalies over the central North Atlantic and north of the Caspian Sea. The EA/WR index was computed by the NOAA climate prediction center according to the rotated principal component analysis used by Barnston and Livezey (1987). The routine meteorological measurements included relative humidity, visibility, and wind speed at the surface that were collected eight times per day. The temperature profile was collected with a sounding balloon twice per day. The calculation procedure for the haze data was consistent with that of Yin et al. (2017), which was mainly based on 
Table 1. Correlation coefficients between the $\mathrm{DHD}_{\mathrm{NH}}$ and key indices from 1979 to 2016 and the ranks of key indices in 2016 . The Corr $\mathrm{Coe}^{1}$ and Corr Coe ${ }^{2}$ indicated that correlation coefficients were calculated after and before detrending. The $\mathrm{I}_{\mathrm{AC}}$ was the anti-cyclone index that was defined as the mean Z500 over $105-125,30-50^{\circ} \mathrm{E}$. The local PBL, surface wind speed, and relative humidity were calculated as the mean over the NH area. All the correlation coefficients were above the $99 \%$ confidence level. The rank was sorted from largest to smallest, when the Corr Coe was positive. If the Corr Coe was negative, the rank was calculated from smallest to largest.

\begin{tabular}{lrrrrrrr}
\hline Index & EA/WR & $\mathrm{I}_{\mathrm{AC}}$ & $\mathrm{PBL}$ & Wind speed & Humidity & SST $_{\mathrm{EP}}$ & Snow $_{\mathrm{WS}}$ \\
\hline Corr Coe $^{1}$ & 0.66 & 0.62 & -0.59 & -0.63 & 0.49 & 0.55 & 0.52 \\
Corr Coe & 0.66 & 0.62 & -0.54 & -0.62 & 0.46 & 0.54 & 0.50 \\
Rank & 3 & 1 & 1 & 6 & 6 & 4 & 1 \\
\hline
\end{tabular}
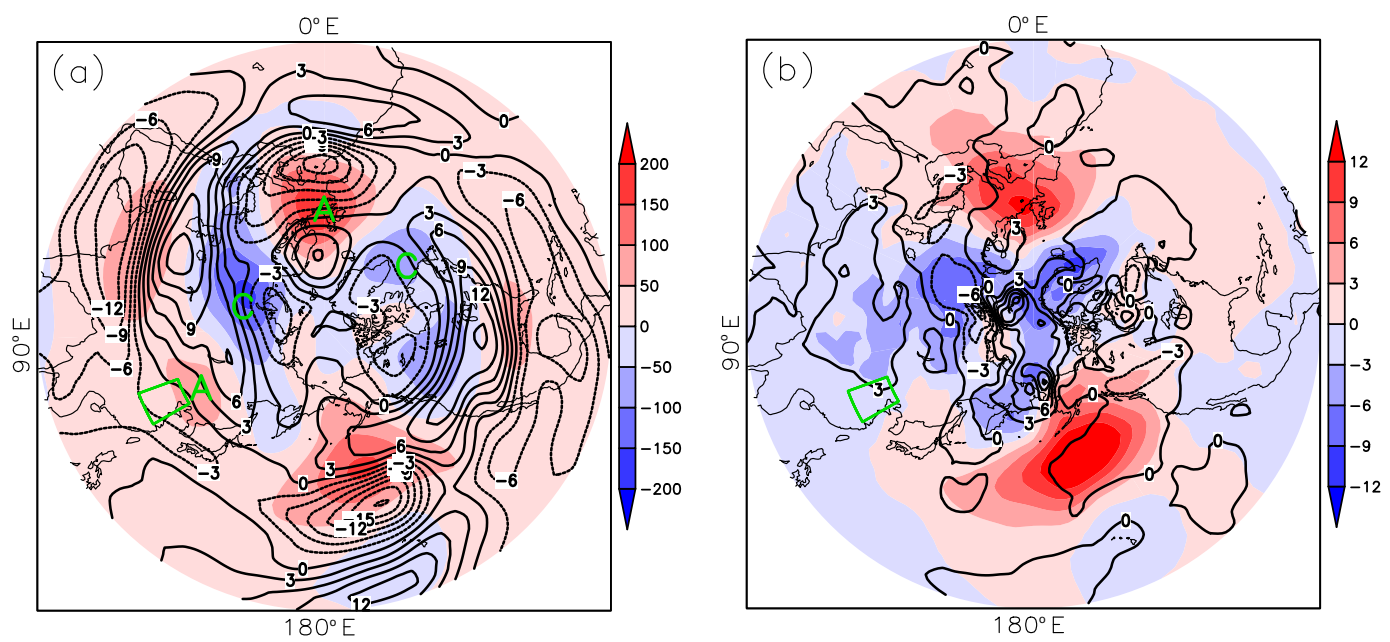

Figure 2. Distribution of the global atmospheric circulation anomalies, (a) Z500 (shading) and U200 (contour) and (b) SLP (shading) and SAT (contour) in December 2016. The anomalies here are calculated with respect to the period from 1981 to 2010.

the observed visibility and relative humidity. Hourly $\mathrm{PM}_{2.5}$ concentration data were downloaded from the website of the Ministry of Environmental Protection of China. Definitions of anomalies are described in the captions for each figure.

\section{Associated atmospheric circulations in December 2016}

Figure 2 shows the distribution of atmospheric circulation anomalies in December 2016. In the upper troposphere, the East Asia jet stream (EAJS) was weaker and northward relative to the mean status, indicating that meridional cold air activity in East Asia was restricted (Chen et al., 2015). As a result, the land surface of East China was warmer (Fig. 2b). On the mid-level, there were positive anomalies of Z500 over Europe and North China and negative centers over the central-North Atlantic and to the north of the Caspian Sea (Fig. 2a). This Rossby wave train resembled the positive phase of the EA/WR pattern. To verify the relationship between the $\mathrm{DHD}_{\mathrm{NH}}$ and the EA/WR pattern, the correlation coefficient was calculated: it was 0.66 from 1979 to 2016 after removing the linear trend and exceeded the $99 \%$ confidence level (Table 1). This positive correlation was stronger than that with winter haze days (i.e., 0.43), as analyzed by Yin et al. (2017). Specific to the positive Z500 anomalies over $105-125,30-50^{\circ} \mathrm{E}$ (i.e., the easternmost center of the EA/WR pattern), the correlation coefficient was 0.62 (Table 1). Thus, the anomalous anti-cyclone over the $\mathrm{NH}$ area in December 2016 could efficiently weaken the vertical motion, resulting in a shallower PBL (Fig. 3a). Furthermore, possible conducive local weather conditions that included the shallow PBL (impacting vertical dispersion), low surface wind speed (impacting horizontal dispersion), and high relative humidity (impacting moisture absorption), whose correlation coefficients with $\mathrm{DHD}_{\mathrm{NH}}$ were $-0.59,-0.63$, and 0.49 from 1979 to 2016, all passed the $99 \%$ confidence test (Table 1). Near the surface, the SLP gradient between Eurasia and the western Pacific decreased (Fig. 2b) and the southerly was induced over the east of China. Warm and humid airflow from the south caused the surface wind speed to be slower and the surface relative humidity to be higher (Fig. 3b). Physically, the positive phase of the EA/WR pattern strengthened the anomalous anti-cyclone over the $\mathrm{NH}$ area and the Japan Sea from the surface to the middle troposphere, resulting in confined vertical motion. The southerly anomalies made the cold air and surface wind speed weaker but enhanced the hu- 

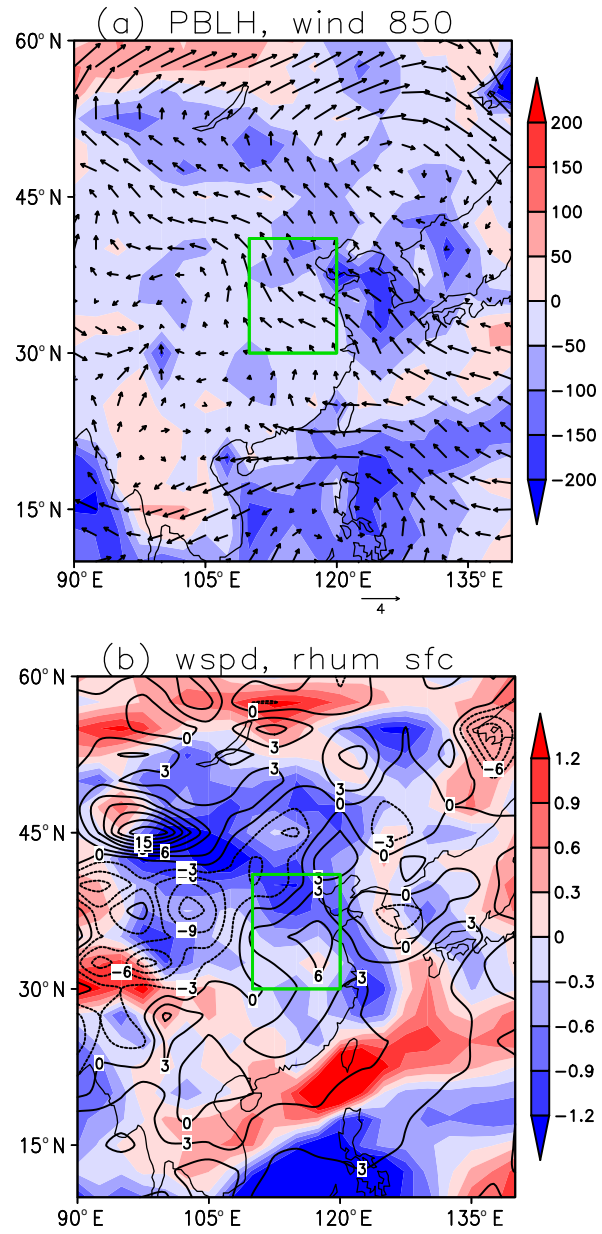

Figure 3. Distribution of the regional atmospheric circulation anomalies, (a) the height of the PBL (shading), and wind at $850 \mathrm{hPa}$ (arrow); and (b) surface wind speed (shading) and surface relative humidity (contour) in December 2016. The anomalies here are calculated with respect to the period from 1981 to 2010 .

mid flow. Under control of such atmospheric circulations and local meteorological conditions, the horizontal and vertical dispersion of atmospheric particulates was suppressed. Thus, the pollutants gathered within a narrow space and the haze occurred frequently. In addition, high humidity supported a beneficial environment for the hygroscopic growth of haze particles. In December 2016, the height of the PBL was lowest and the intensity of the anomalous anti-cyclone over the $\mathrm{NH}$ was strongest (Table 1), indicating that the vertical dispersion condition of pollutants was weakest during the past 38 years. The other key indices (i.e., the EA/WR index, surface wind speed, and surface relative humidity) were all in the top six. Thus, the atmospheric circulations and local meteorological conditions were strongly beneficial for haze occurrence and combined to result in the severest haze events in December 2016.
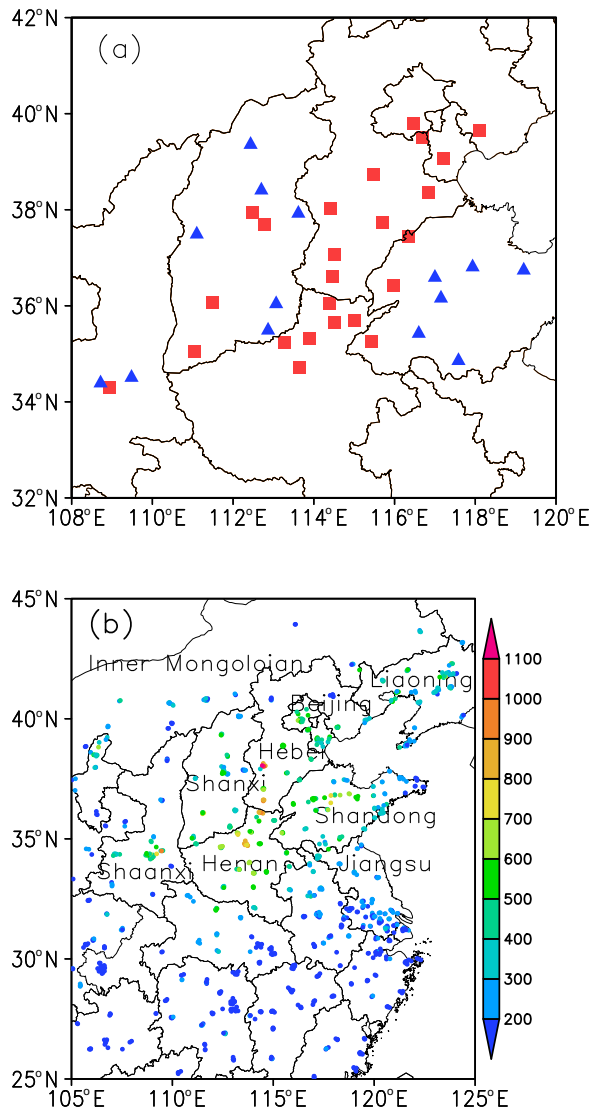

Figure 4. (a) The measures to limit anthropogenic emissions and (b) the maximum hourly $\mathrm{PM}_{2.5}$ concentration during 16-21 December 2016. In panel (a), the red rectangle indicates both the vehicle control and production restriction measures that were implemented, while the blue triangle indicates the production that was restricted. The letters in panel (b) were the names of the provinces.

\section{A synoptic case study}

On 15 December 2016, the Ministry of Environmental Protection of China warned that severe haze pollution would occur over the $\mathrm{NH}$ area in the coming week. After that, nearly 30 cities were issued an air pollution red (the highest level) warning, and another 20 cities were issued an orange (the second level) warning (figure omitted). There was a haze-prone zone located from southwest to northeast, i.e., from the north of Henan Province to Beijing. In this haze-prone zone, vehicle control and production restriction measures were both strictly implemented. In the surrounding cities, the industrial production was also restricted (Fig. 4a). These regulatory measures were distributed according to the measured $\mathrm{PM}_{2.5}$ concentration, illustrating good scientific-based decision-making and management. Anthropogenic emissions were also more stringently limited at this time than for other haze weather processes that had occurred during the same year, but the most severe haze pol- 


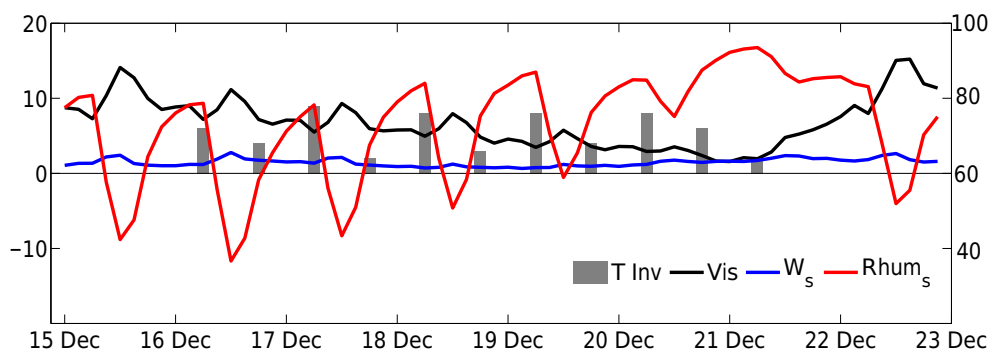

Figure 5. The variation of area-mean visibility (black), surface wind speed (blue), and surface relative humidity (red, right $y$-axis). The intensity of the temperature inversion $\left(T_{925}-T_{1000}\right)$ in Beijing is shown as a gray bar.
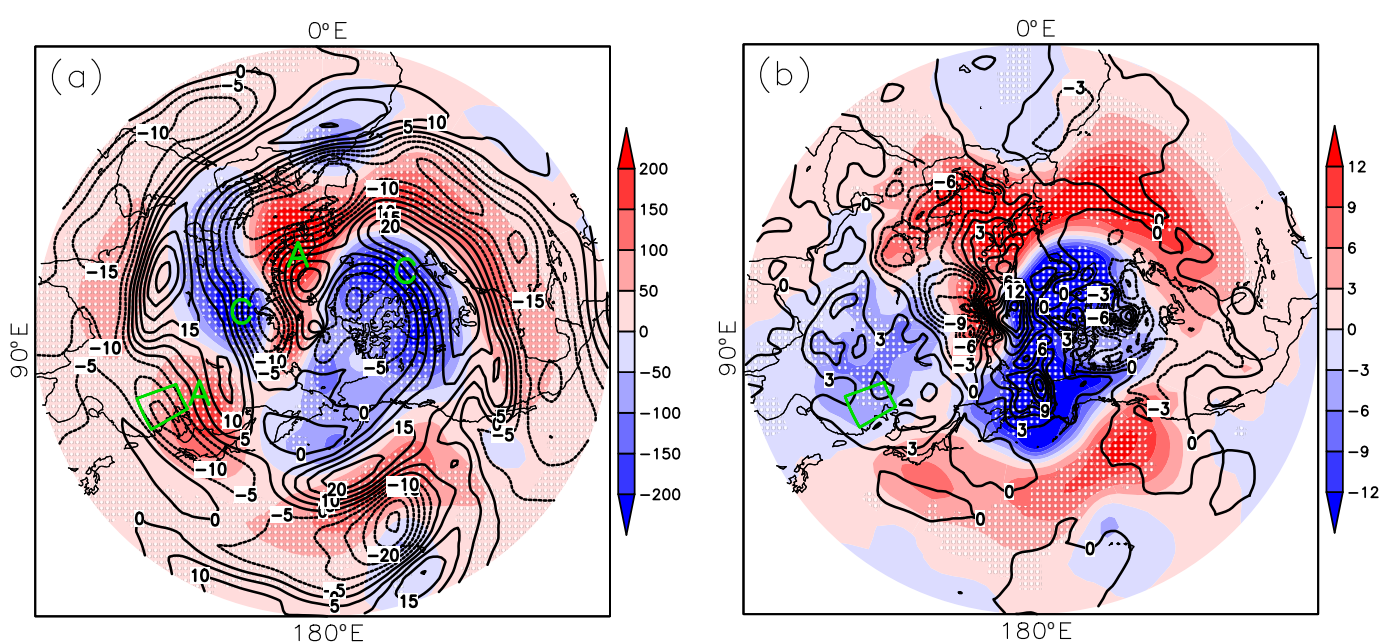

Figure 6. Distribution of the global atmospheric circulation anomalies, (a) Z500 (shading) and U200 (contour); the white dots indicate Z500 anomalies exceeding the $95 \%$ confidence level ( $t$ test), and (b) SLP (shading) and SAT (contour) during 16-21 December 2016; the white dots indicate SLP anomalies exceeding the $95 \%$ confidence level ( $t$ test). The anomalies here are calculated with respect to the period of 1981-2010.

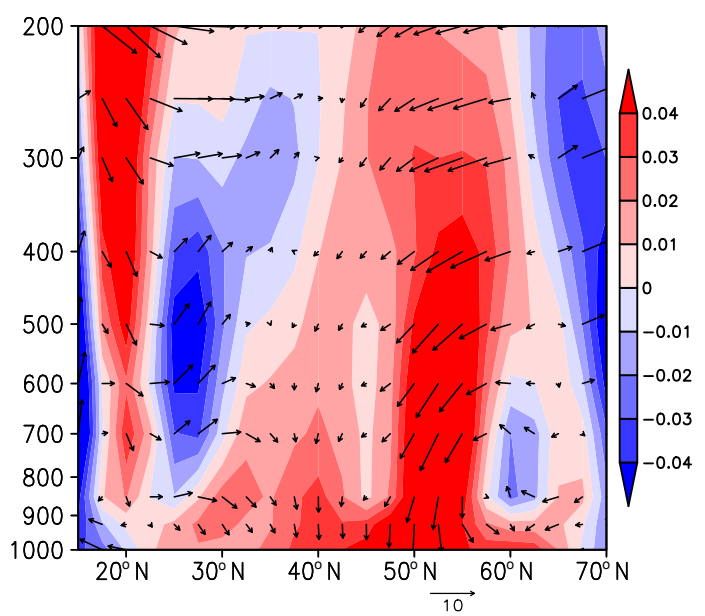

Figure 7. Vertical-latitude section $\left(110-120^{\circ} \mathrm{E}\right.$ mean $)$ of wind during 16-21 December 2016: omega (shading) and wind (arrow, omega was magnified 100 times). lution still occurred. The highest $\mathrm{PM}_{2.5}$ concentration (i.e., $1100 \mu \mathrm{g} \mathrm{m}^{-3}$ ) was observed in Shijiazhuang, the provincial capital of Hebei Province (Fig. 4b). The measured maximum hourly $\mathrm{PM}_{2.5}$ concentrations over the $\mathrm{NH}$ area were almost above $500 \mu \mathrm{g} \mathrm{m}^{-3}$, which was beyond the level of severe air pollution for China. Furthermore, there were three groups of stations with $\mathrm{PM}_{2.5}$ concentrations greater than $700 \mu \mathrm{g} \mathrm{m}{ }^{-3}$, and these were in the central Shaanxi Province, the north of Henan Province and the south of Hebei Province, and the central Shandong Province. In addition, the coverage for this haze pollution process was quite large. Spreading to the south, $\mathrm{PM}_{2.5}$ concentrations larger than $300 \mu \mathrm{g} \mathrm{m}^{-3}$ could be observed in most sites in Jiangsu Province. Around the northern edge of the haze area, high $\mathrm{PM}_{2.5}$ concentrations occurred in Liaoning Province and Inner Mongolia.

Low visibility is another representation of haze that is widely used in meteorology. Area-averaged visibility was lower than $10 \mathrm{~km}$, and haze pollution was gradually aggravated from 16 to 21 December (Fig. 5). During 16-18 December, the diurnal variation of visibility was obvious; i.e., visibility decreased at night and increased a little in the morn- 


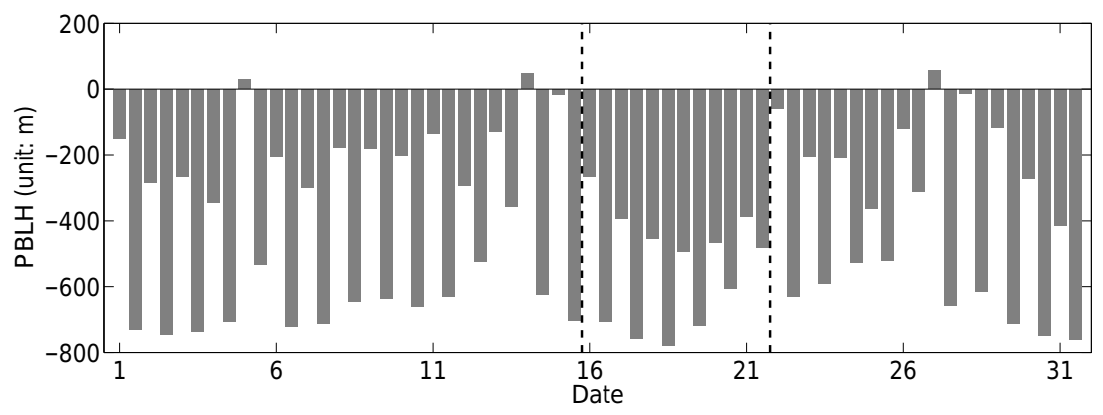

Figure 8. The variation of the area-mean anomalous height of the PBL in December 2016. The anomalies here are twice a day and calculated with respect to the December mean PBLH from 1981 to 2010.

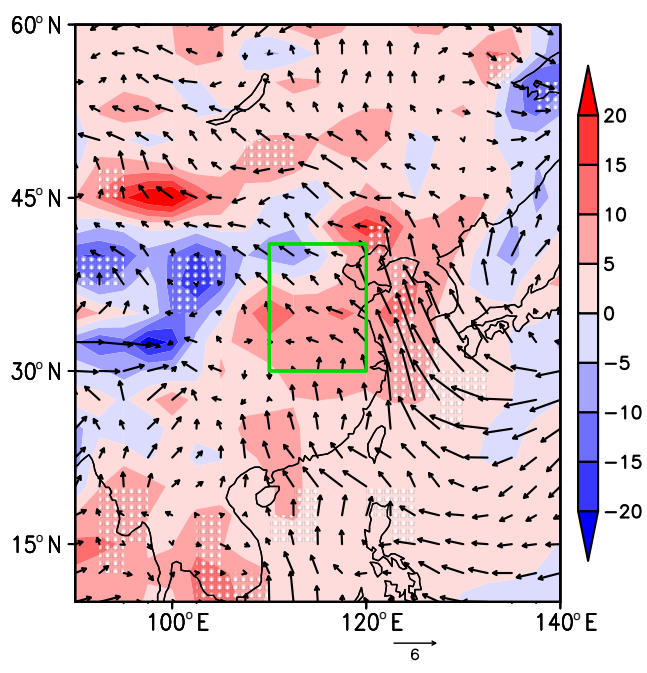

Figure 9. Distribution of the regional atmospheric circulation anomalies, surface wind (arrow), and surface relative humidity (shading) during 16-21 December 2016. The white dots indicate surface relative humidity anomalies exceeding the $95 \%$ confidence level ( $t$ test). The anomalies here are calculated with respect to the period from 1981 to 2010 .

ing. Then, visibility decreased persistently and to a minimum value on 21 December. The correlation coefficient between visibility and surface wind speed (surface relative humidity) was $0.4(-0.69)$, passing the $99.99 \%$ confidence test. The continuous low surface wind speed $\left(<2 \mathrm{~m} \mathrm{~s}^{-1}\right)$ restrained the horizontal dispersion of aerosols, and high humidity in the environment promoted hygroscopic growth that dramatically reduced visibility. The intensity of the temperature inversion remained positive for $132 \mathrm{~h}$ and reached $9{ }^{\circ} \mathrm{C}$ on 20 December, so atmospheric particles were limited to a shallow PBL and accumulated easily. The meteorological conditions also showed obvious diurnal variation during the early stage of this haze process. Relative humidity was continuously above $80 \%$ after 20 December, resulting in persistent decreasing and a minimum value of visibility.
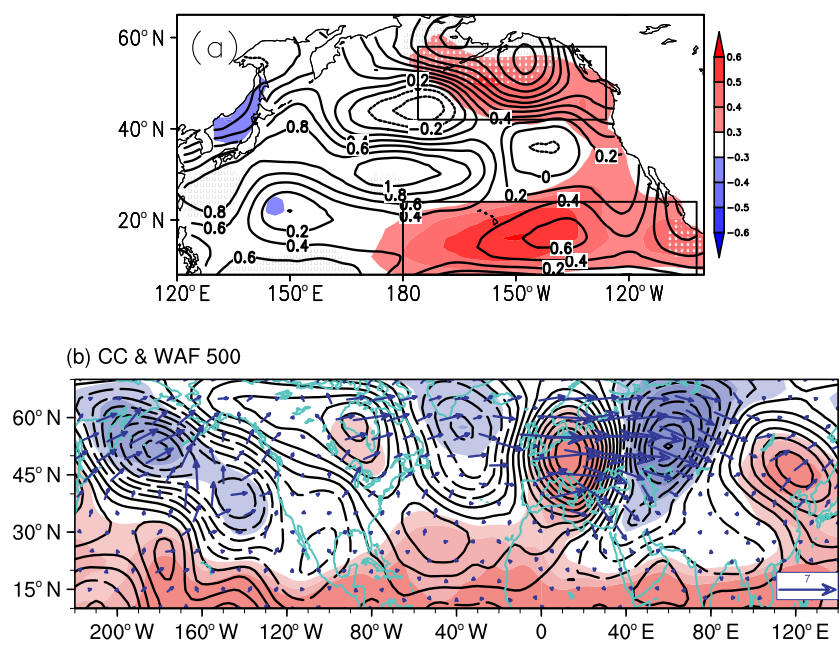

Figure 10. (a) The correlation coefficients (shading) between the preceding autumn SST and DHD $\mathrm{NH}$, and the anomalous SSTs in 2016 (contour) that are calculated with respect to the period from 1979 to 2016 , and (b) the correlation coefficients between $\mathrm{SST}_{\mathrm{EP}}$ and Z500 exceeding the $90 \%$ confidence level (shading), correlated WAF (arrow), and quasi-geostrophic stream function (contour) at $500 \mathrm{hPa}$ in December.

The anomalies of atmospheric circulation during 16-21 December were similar to those throughout December, but they were more evident and much stronger than the mean status in December 2016 that resulted in the severest December haze. The EAJS was weaker than the mean status and moved northward, resulting in weak cold air activity and a warmer surface (Fig. 6). In the middle troposphere, the EA/WR pattern could be clearly recognized, and the anomalous anticyclone over North China and Japan was very strong. Under their influence, there was a descending motion from 30 to $55^{\circ} \mathrm{N}$ (Fig. 7), and the height of the PBL was approximately $400 \mathrm{~m}$ lower than the mean status of December (Fig. 8). Furthermore, the anomalous height was almost negative in all months. In addition to vertical accumulation, there was northward and horizontal transportation of atmospheric particles from the surface to $950 \mathrm{hPa}$ (Fig. 7). Near the surface, 


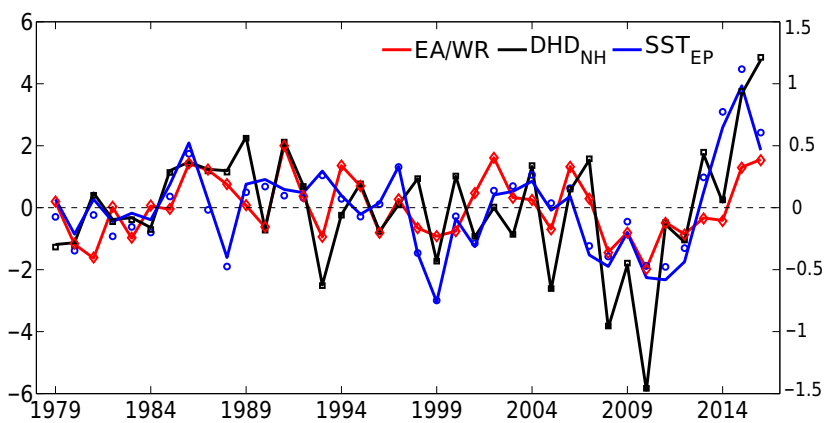

Figure 11. Variation of the $\mathrm{DHD}_{\mathrm{NH}}$ (black), EA/WR pattern (red), and SST $_{\mathrm{EP}}$ (blue) indices from 1979 to 2016. The solid lines indicate the indices whose linear trends were removed and the symbols without lines were the original indices.

the SLP of the mid-high latitude was distributed as the positive phase of the Arctic Oscillation (AO) pattern and the cold air of the polar regions was toward the Aleutian Islands, so the cold air was difficult to move southward to the NH area. The gradient of SLP (SAT) between Eurasia and the western Pacific receded. The stimulated southerly over the East China coastal area not only weakened the surface wind speed, but also led to high humidity over the NH area. In summary, during 16-21 December, atmospheric circulations resulted in local weather conditions highly conducive to severe haze pollution over the $\mathrm{NH}$ area.

\section{Discussion and conclusions}

The most forceful controlling measures of anthropogenic emissions in 2016 were implemented during 16-21 December, but the severest haze pollution still occurred, covering approximately $25 \%$ of the land area of China and lasting for 6 days. The highest $\mathrm{PM}_{2.5}$ concentration observed was $1100 \mu \mathrm{g} \mathrm{m}^{-3}$. Thus, it was hypothesized that atmospheric circulation must play a critical role. Our results verified that a weaker and northward EAJS led to weak cold air activity. In the middle troposphere, the positive phase of the EA/WR pattern was evident, and it stimulated a descending motion from 30 to $55^{\circ} \mathrm{N}$ and a lower PBL over the $\mathrm{NH}$ area. Near the surface, the positive phase of the AO pattern made the cold air move southward. The anomalous southerly not only weakened the surface wind speed, but also led to high humidity over the $\mathrm{NH}$ area. The atmospheric circulations were very conducive to severe haze pollution over the $\mathrm{NH}$ area. During all of December, the number of $\mathrm{DHD}_{\mathrm{NH}}$ increased sharply from 2010 and was greatest in 2016. The associated atmospheric circulations that were verified by climatic correlation analysis were similar. In other words, there was a weaker EAJS in the upper troposphere, a positive phase of the EA/WR pattern in the middle troposphere, and conducive local weather conditions (lower PBL, low surface wind speed, and abundant moisture).
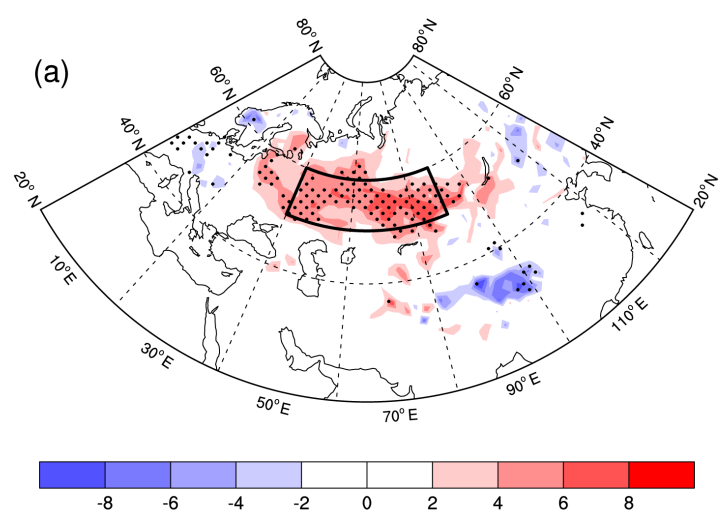

(b)CC \& WAF 500

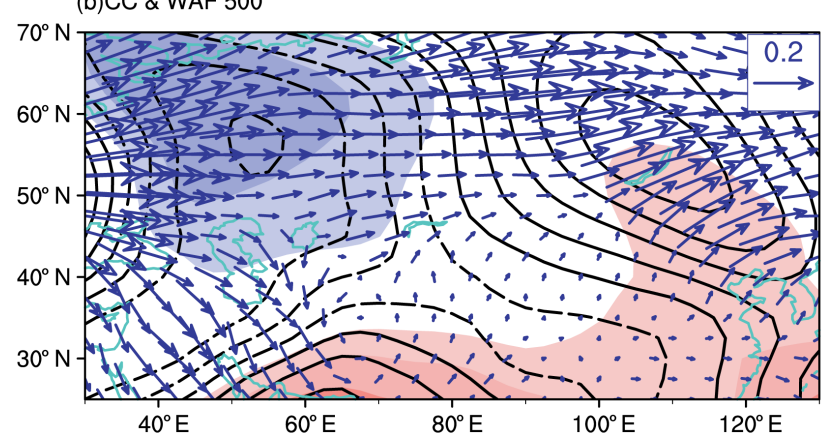

Figure 12. (a) The correlation coefficients (shading) between the October-November snow cover and $\mathrm{DHD}_{\mathrm{NH}}$. The dots indicate the correlation coefficients exceeding the $95 \%$ confidence level ( $t$-test), and (b) the correlation coefficients between snow WS and Z500 exceeding the $90 \%$ confidence level (shading), correlated WAF (arrow), and quasi-geostrophic stream function (contour) at $500 \mathrm{hPa}$ in December.

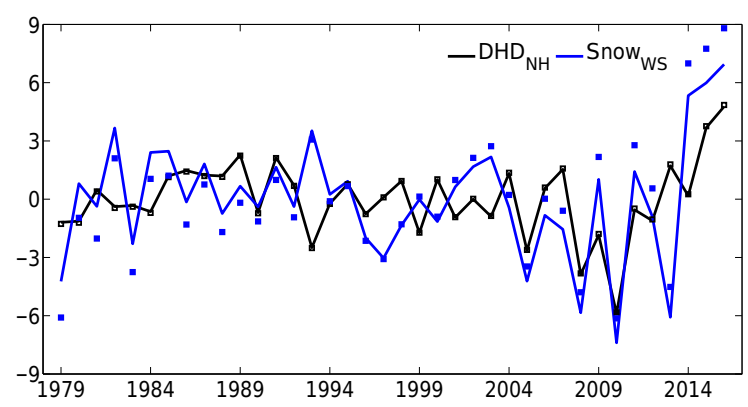

Figure 13. Variation of the $\mathrm{DHD}_{\mathrm{NH}}$ (black) and Snowws (blue) indices from 1979 to 2016 . The solid lines indicate the indices whose linear trends were removed and the symbols without lines are the original indices.

The preceding autumn SST in the Pacific significantly influenced the winter haze days in North China (Yin et al., 2016) and could partly explain the severe haze pollution during the winter of 2014 (Yin et al., 2017). For December, the significantly correlated SST with $\mathrm{DHD}_{\mathrm{NH}}$ was located near the Gulf of Alaska and the subtropical eastern Pacific (Fig. 10a). The preceding autumn SST of these two areas 
was averaged as an index ( $\left.\mathrm{SST}_{\mathrm{EP}}\right)$, and the correlation coefficients with December Z500 were calculated and are shown in Fig. 10b. The EA/WR pattern, especially the anomalous anticyclone over NH and Japan, was obvious. The correlation coefficient between $\mathrm{SST}_{\mathrm{EP}}$ and the EA/WR index $\left(\mathrm{DHD}_{\mathrm{NH}}\right)$ was $0.48(0.55)$ after detrending; thus, we speculated that the $\mathrm{SST}_{\mathrm{EP}}$ influenced $\mathrm{DHD}_{\mathrm{NH}}$ by modulating the EA/WR pattern. The positive SST anomalies near the Gulf of Alaska and the subtropical eastern Pacific could impact the wave activity flux (WAF) and (Fig. 10b) stimulated a Rossby wavelike pattern propagating from the eastern Pacific, through North America and the Atlantic, and to East Asia. The atmospheric action centered over the North Atlantic and Eurasia overlapped with that of the EA/WR teleconnection pattern. Therefore, the positive phase of the EA/WR pattern could be stimulated or enhanced by positive $\mathrm{SST}_{\mathrm{EP}}$ and then lead to weak ventilation conditions that were beneficial for the occurrence of haze. In 2016, the positive $\mathrm{SST}_{\mathrm{EP}}$ in autumn were consistent with the positive correlation fields, leading to more $\mathrm{DHD}_{\mathrm{NH}}$. Furthermore, the $\mathrm{DHD}_{\mathrm{NH}}$ varied with an obvious decreasing trend from 2006 to 2010, and with a dramatic increasing trend after 2010. The variation of the $\mathrm{EA} / \mathrm{WR}$ and $\mathrm{SST}_{\mathrm{EP}}$ index exhibited similar features. During the most recent 10 years, the EA/WR pattern was distributed as its strongest negative phase in 2010 and strongest positive phase in 2016, which was consistent with the variation of $\mathrm{DHD}_{\mathrm{NH}}$ (Fig. 11). The variation of the EA/WR pattern could largely explain the trend break of $\mathrm{DHD}_{\mathrm{NH}}$. As shown by Gao and Chen (2017), October SST anomalies near the Gulf of Alaska and the subtropical eastern Pacific contributed to the haze pollution over North China in October 2016. Impacts of the $\mathrm{SST}_{\mathrm{EP}}$ on ventilation conditions were robust and could continue into December. Furthermore, the relationships with autumn SST in the Atlantic were also found to be weaker and significant only in small regions (figure omitted).

The Eurasian snowpack and atmospheric circulation dominant modes were stably coupled from autumn to the subsequent spring (Sun, 2017), so the role of the preceding October-November (ON) snow cover was also examined (Fig. 12). The snow cover over western Siberia (Snowws) was significantly correlated with DHD $_{\mathrm{NH}}$ (EA/WR; Fig. 12a); i.e., the correlation coefficient was 0.52 (0.45) after detrending (Table 1). More snow was correlated with a higher albedo, resulting in a colder land surface. When there was higher Snowws, negative Z500 anomalies over western Siberia and positive anomalies over eastern China, i.e., the two active centers of the EA/WR pattern in the east, were significantly stimulated. The WAF associated with positive Snowws anomalies was evidently induced near western Siberia and efficiently propagated westwards, and stimulated an obvious anti-cyclone over Baikal Lake and the NH area (Fig. 12b). The Snowws varied similarly with $\mathrm{DHD}_{\mathrm{NH}}$ and achieved its maximum (minimum) in 2016 (2010). As revealed by Wang et al. (2015) and Yin et al. (2017), the preceding autumn Arctic sea ice has a close relationship with the winter haze days in the east of China. The climatic relationship between the Arctic sea ice and $\mathrm{DHD}_{\mathrm{NH}}$ and the anomalies in December were also examined and found to be insignificant (figure omitted). This may be due to the relationship being different in the early and late winter, which requires more research in the future. The detailed mechanisms between the external forcings and haze pollution should be studied physically and dynamically in future work. Furthermore, although anthropogenic emissions were limited during haze pollution events, there were still aerosols being discharged into the atmosphere by the dense population and industry before and during 16-21 December. There is little doubt that the high concentration of $\mathrm{PM}_{2.5}$ was the fundamental cause of haze pollution, and the associated atmospheric anomalies played key roles in the severe haze pollution events. The previous accumulation of atmospheric particles also contributed to the occurrence of haze pollution events. As revealed in this study, it was difficult to modify the simultaneous atmospheric circulations, which significantly contributed to the haze. Therefore, the controlling measures of anthropogenic emissions should be implemented in advance to reduce the stock of aerosols in the atmosphere.

Data availability. Atmospheric data are available from the NCEP/NCAR data archive: http://www.esrl.noaa.gov/psd/ data/gridded/data.ncep.reanalysis.html (NCEP/NCAR, 2017). SST data are downloaded from http://www.esrl.noaa.gov/psd/ data/gridded/data.noaa.ersst.v4.html (NOAA, 2017). Snow cover data can be downloaded from Rutgers University: http://climate.rutgers.edu/snowcover/ (Rutgers, 2017). The monthly EA/WR and WP indices (CPC, 2017) can be downloaded from NOAA's Climate Prediction Center: http://www.cpc.ncep. noaa.gov/data/teledoc/telecontents.shtml. The ground observations are from the website http://data.cma.cn/ (CMA, 2017). The monthly PBLH data are available on the ERA-Interim website: http://www.ecmwf.int/en/research/climate-reanalysis/era-interim (ERA-Interim, 2017). The atmospheric composition data can be obtained from the authors.

Competing interests. The authors declare that they have no conflict of interest.

Acknowledgements. This research was supported by the National Key Research and Development Plan (2016YFA0600703), the National Natural Science Foundation of China (41421004, 41705058), the CAS-PKU Partnership Program, the Startup Foundation for Introducing Talent of Nanjing University of Information Science and Technology (20172007), the KLME Open Foundation (KLME1607), and the Priority Academic Program Development of Jiangsu Higher Education Institutions (PAPD).

Edited by: Jianping Huang

Reviewed by: two anonymous referees 


\section{References}

Barnston, A. G. and Livezey, R. E.: Classification, seasonality and persistence of low frequency atmospheric circulation patterns, Mon. Weather Rev., 115, 1083-1126, 1987.

Cai, W. J., Li, K., Liao, H., Wang, H. J., and Wu, L. X.: Weather Conditions Conducive to Beijing Severe Haze More Frequent under Climate Change, Nature Climate Change, 7, 257-263, https://doi.org/10.1038/nclimate3249, 2017.

Chen, H. P. and Wang, H. J.: Haze days in North China and the associated atmospheric circulations based on daily visibility data from 1960 to 2012, J. Geophys. Res.-Atmos., 120, 5895-5909, https://doi.org/10.1002/2015JD023225, 2015.

CMA: Ground observations, available at: http://data.cma.cn/, last access: 25 September 2017

CPC: EA/WR and WP indices, available at: http://www.cpc. ncep.noaa.gov/data/teledoc/telecontents.shtml, last access: 25 September 2017.

ERA-Interim: PBLH data, available at: http://www.ecmwf.int/en/ research/climate-reanalysis/era-interim, last access: 25 September 2017.

Dee, D. P., Uppala, S. M., Simmons, A. J., Berrisford, P., Poli, P., Kobayashi, S., Andrae, U., Balmaseda, M. A., Balsamo, G., Bauer, P., Bechtold, P., and Beljaars, A. C. M.: The ERAInterim reanalysis: configuration and performance of the data assimilation system, Q. J. Roy. Meteor. Soc., 137, 553-597, https://doi.org/10.1002/qj.828, 2011.

Ding, Y. H. and Liu, Y. J.: Analysis of long-term variations of fog and haze in China in recent 50 years and their relations with atmospheric humidity, Sci. China Ser. D, 57, 36-46, 2014 (in Chinese).

Gao, Y. and Chen, D.: A dark October in Beijing 2016, Atmos. Ocean. Sci. Lett., 10, 206-213, 2017.

Kalnay, E., Kanamitsu, M., Kistler, R., Collins, W., Deaven, D., Gandin, L., Iredell, M., Saha, S., White, G., Woollen, J., Zhu, Y., Leetmaa, A., Reynolds, R., Chelliah, M., Ebisuzaki, W., Higgins, W., Janowiak, J., Mo, K. C., Ropelewski, C., Wang, J., Jenne, R., and Joseph, D.: The NCEP/NCAR 40-year reanalysis project, B. Am. Meteorol. Soc., 77, 437-471, https://doi.org/10.1175/15200477(1996)077<0437:TNYRP>2.0.CO;2, 1996.

Li, Q., Zhang, R. H., and Wang, Y.: Interannual variation of the winter-time fog-haze days across central and eastern China and its relation with East Asian winter monsoon, Int. J. Climatol., 36, 346-354, https://doi.org/10.1002/joc.4350, 2015.

Mathews, J. and Tan, H.: China's Renewable Energy Revolution, Basingstoke: Palgrave Macmillan, 2015.

NOAA: SST data, available at: http://www.esrl.noaa.gov/psd/data/ gridded/data.noaa.ersst.v4.html, last access: 25 September 2017.

NCEP/NCAR: Atmospheric data, available at: http://www. esrl.noaa.gov/psd/data/gridded/data.ncep.reanalysis.html, last access: 25 September 2017

Robinson, D. A., Dewey, K. F., and Heim Jr., R.: Global snow cover monitoring: an update, B. Am. Meteorol. Soc., 74, 1689-1696, 1993.
Rutgers University: Snow cover data, available at: http://climate. rutgers.edu/snowcover/, last access: 25 September 2017.

Smith, T., Reynolds, R., Peterson, T., and Lawrimore, J.: Improvements to NOAA's historical merged land-ocean surface temperature analysis (1880-2006), J. Climate, 21, 2283-2296, 2008.

Sun, B.: Seasonal evolution of the dominant modes of the Eurasian snowpack and atmospheric circulation from autumn to the subsequent spring and the associated surface heat budget, Atmos. Ocean. Sci. Lett., 10, 191-197, 2017.

Wang, H.-J. and Chen, H.-P.: Understanding the recent trend of haze pollution in eastern China: roles of climate change, Atmos. Chem. Phys., 16, 420—4211, https://doi.org/10.5194/acp16-4205-2016, 2016.

Wang, H. J., Chen, H. P., and Liu, J. P.: Arctic sea ice decline intensified haze pollution in eastern China, Atmos. Ocean. Sci. Lett., 8, 1-9, 2015

Wang, Y. S., Yao, L., Liu, Z. R., Ji, D. S., Wang, L. L., and Zhang, J. K.: Formation of haze pollution in Beijing-Tianjin-Hebei region and their control strategies, B. Chinese Acad. Sci., 28, 353-363, 2013.

Wu, P., Ding, Y. H., and Liu, Y. J.: Atmospheric circulation and dynamic mechanism for persistent haze events in the BeijingTianjin-Hebei region, Adv. Atmos. Sci., 34, 429-440, 2017.

Yang, Y., Liao, H., and Lou, S.: Increase in winter haze over eastern China in recent decades: Roles of variations in meteorological parameters and anthropogenic emissions, J. Geophys. Res.Atmos., 121, 13050-13065, 2016.

Yin, Z. C. and Wang, H. J.: The relationship between the subtropical Western Pacific SST and haze over NorthCentral North China Plain, Int. J. Climatol., 36, 3479-3491, https://doi.org/10.1002/joc.4570, 2016.

Yin, Z. C., Wang, H. J., and Guo, W. L.: Climatic change features of fog and haze in winter over North China and Huang-Huai Area, Sci. China Earth Sci., 58, 1370-1376, 2015a.

Yin, Z. C., Wang, H. J., and Yuan, D. M.: Interdecadal increase of haze in winter over North China and the Huang-huai area and the weakening of the East Asia winter monsoon, Chin. Sci. Bull., 60, 1395-1400, 2015b (in Chinese).

Yin, Z. C., Wang, H. J., and Chen, H. P.: Understanding severe winter haze events in the North China Plain in 2014: roles of climate anomalies, Atmos. Chem. Phys., 17, 1641-1651, https://doi.org/10.5194/acp-17-1641-2017, 2017.

Zhang, X. Y, Sun, J. Y., Wang, Y. Q., Li, W. J., Zhang, Q., Wang, W. G., Quan, J. N., Cao, G. L., Wang, J. Z., Yang, Y. Q., and Zhang, Y. M.: Factors contributing to haze and fog in China, Chin. Sci. Bull., 58, 1178-1187, 2013 (in Chinese).

Zhou, L. H., Zhang, X. Y., Zhang, J., Zhu, S. G., and Meng, X. Y.: A case study of air quality control in Beijing and the surrounding area during the 2015 World Championships and Parade, Atmos. Ocean. Sci. Lett., 10, 252-260, 2017. 